\title{
Swimming Learning Model for Elementary School Students who are Not Brave to Swim
}

\author{
$1^{\text {st }}$ Abdul Sukur \\ Departement Coaching Sport Education \\ Faculty of Sport Science Jakarta State \\ University \\ Jakarta, Indonesia \\ abdulsukur69@yahoo.com
}

\author{
$2^{\text {nd }}$ Ika Novitaria \\ Departement Coaching Sport Education \\ Faculty of Sport Science Jakarta State \\ University \\ Jakarta, Indonesia \\ ikanovi1979@gmail.com
}

\author{
$3^{\text {rd }}$ Hamim Khiara Ananda \\ Degree College Student of Postgraduates \\ Study Program \\ Jakarta State University \\ Jakarta, Indonesia
}

\begin{abstract}
Swimming is one of the materials in physical education taught to elementary school students. However, many elementary school students are not brave when having to learn swimming for various reasons. Therefore, this study was conducted with the aim to produce a model of swimming learning for elementary school students who are not brave to swim. This research was using research and development method from Borg and Gall. Subjects in this research are elementary school students consisting of 30 children. The instrument used in this research is a questionnaire and Modified test of water. The stages in this research are: (1) needs analysis, (2) expert evaluation (initial product evaluation); (3) limited trials (small group trial); (4) product revision and (5) main test (field testing). Based on the results of the study it can be concluded that: pool learning model developed can be applied to elementary school students so they dare to swim.
\end{abstract}

Keywords - Learning Model, Swimming, Elementary School Student.

\section{INTRODUCTION}

Physical education is essentially an educational process that utilizes physical activity to produce a holistic change in the quality of the individual, both in physical, mental and emotional. Physical education emphasizes the whole aspects of education (health, physical fitness, critical thinking skills, emotional stability, social skills, reasoning and moral action). Physical education [1] is a medium to encourage the development of motor skills, physical abilities, knowledge, reasoning, appreciation of values (attitude-mental-emotionalspiritual-social), and habituation of healthy lifestyles that lead to stimulating balanced growth and development.

Bucher [2] stated that physical education is an integral part of the entire educational process, which has the goal of developing physical, mental, emotional and social citizens through physical activity that has been chosen to realize those goals. "Physical education It is important to recognise that there are two types of aims: first, those which are unique to physical education, intrinsic to the subject and see physical education as an end in itself; and, second, those which the subject shares with other aspects of the curriculum, are extrinsic to physical education and use the subject as a means to broader educational goals"'[3].

According to BSNP [4] the scope of physical, sports and health education subjects for elementary / MI are as follows: (1) Games and sports include: traditional sports, games, motion explorations, non locomotor, and manipulative, athletics, soccer, basketball, volleyball, tennis, field tennis, badminton, and martial arts, and other activities. (2) Development activities include body attitude mechanics, physical fitness component, posture shape and other activities. (3) Gymnastics activities include simple dexterity with no tools, dexterity with tools, and gymnastics floor, and other activities. (4) Ritmic activities include free movement, morning gymnastics, SKJ, and aerobic gymnastics, and other activities. (5) Water activities include games in water, water safety, water movements, and swimming and other activities. (6) outdoor education includes picnic/field trip, introduction, introduction to the environment, camping, exploring and mountain climbing. (7) health includes: the cultivation of a healthy living culture in everyday life, especially those related to body care to stay healthy, nurturing a healthy environment, choosing healthy foods and drinks, preventing and treating injuries, arranging proper rest time and taking an active role in $\mathrm{P} 3 \mathrm{~K}$ and UKS activities, the health aspect is a separate aspect, and implicitly enters all aspects.

Based on the explanation above, then swim into one of the subjects taught in physical education at school. Swimming is not only a sport, but also a means to fill the spare time for pleasure oneself or for achievement. Understanding swimming is a movement to defend yourself in the water so as not to 
drown while in the water. According to Putra [5] "the benefits of swimming are: 1) Eliminate the fear of water, 2) Means of play, 3) nourish the body and stimulate the motoric movement, 4) sharpening independence, courage and confidence, 5) Improving social skills". However, one obstacle for children to be able to achieve the determined swimming competence is to have the fear of swimming.

Fear is the psychological symptoms that arise from within oneself. Fear, when allowed to be more severe, is characterized by fear arising from the subconscious. Fear can come from both yourself and from outside. The fear of swimming is a fear because of things related to swimming, such as fear of drowning, fear of water with a lot of volumes, and other causes. Basically, the fear of water because it faces a new environment. To overcome the fear of water can be done by gradually manipulating the environment, that is by understanding the water itself. The fear to swim for a child for fear of drowning or fear of water can be minimized by the right approach with creative creativity required in a varied and appropriate approach to learning. Varied learning approach in this study is a gradual and inclusive approach that is tailored to the characteristics of elementary school age students. Thus, in this study, researchers will develop a model of swimming learning appropriate and varied to overcome the problem of swimming learning in elementary school-age students who dare not swim.

\section{MATERIALS AND METHODS}

The method used is a method of research and development. According to Borg \& Gall, the method of research and development is a process used to develop and validate educational products [6]. The result of this research development method is to produce learning model that is used in swimming learning activities with the aim to help teachers in delivering learning materials so as to achieve the expected learning outcomes. Research development is not a research to test the theory but an attempt to develop a product so that it becomes effective and can be used as learning in school. The steps of development model as follows:

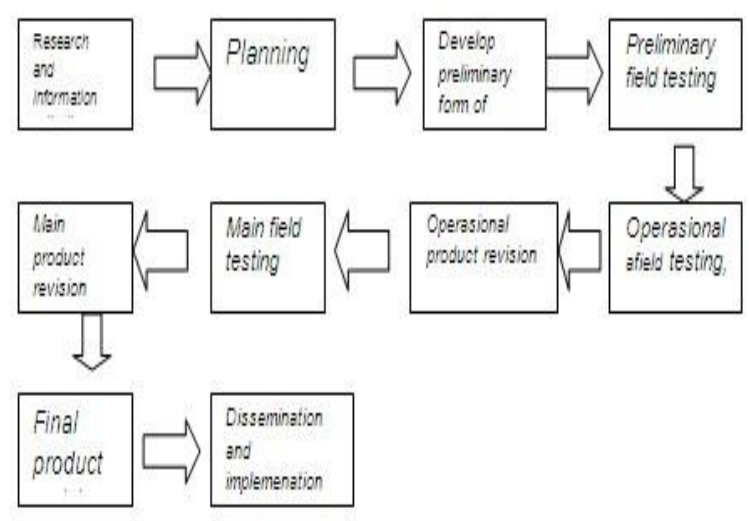

Fig.1 Methods of Borg and Gall.

The research subjects used were elementary school students Pinang Ranti 03 Petang. To know the potentials and problems, then the needs analysis by using interviews and questionnaires to elementary school students Pinang Ranti 03 Petang. After obtaining the result of requirement analysis, then the data collected as a foundation to make the draft of elementary school age learning model After doing the data collecting phase and making the draft of elementary school age learning model that did not dare to swim, the next step is to test the expert where the intended purpose is achieved by obtaining the feasibility or validity of the model made by direct assessment from the experts by presenting 3 experts. The next step after the model revision phase II of the expert then proceeded to test the product to large groups by using research subjects as many as 30 elementary school students consisting of 3 primary schools, SDN Pinang Ranti 03 Petang East Jakarta, SDN Pinang Ranti 01 Pagi East Jakarta and SDN Makassar 06 Pagi East Jakarta.

\section{RESULTS AND DISCUSSION}

In accordance with the stages in research and development methods used it can be known the results of the study as follows: The needs analysis results show that: there are $32.55 \%$ 5th-grade students who cannot swim, and $29.41 \%$ of them have the fear to swim. (2) the students had never received the model of swimming learning that was fun, (3) the students were happy with the swimming materials, (4) the students had never get swimming learning models during swimming, (5) students agree when developed swimming learning models for elementary school-age children who dare not swim. Thus it is necessary for a real effort to solve the problem. Because swimming is one of the important skills for students as a supporter of the growth period, but also able to be an effort to equip themselves for saving themselves in the water environment.

The next step is to test the validity conducted by experts. Based on the validity test, it can be concluded that the variation of swimming learning model for elementary school students who dare not to swim feasible and can be used in elementary school age balance learning. Expert test conducted by researchers of the two experts, there are several constructive suggestions to enhance the balance of primary school-age models among which:

1) The implementation guidelines should be made clear so that they are easy to understand.

2) The model used in the drawing should be elementary school age children.

3) Applied models must be systematic and gradual from easy activities too difficult or complex activities.

4) The swimming learning model should be documented with an authentic photo.

The next step after the model was revised phase II of experts then proceed with the testing of the product to the large group using the study subjects were 30 elementary school students consisting of three primary schools, SDN Pinang Ranti 03 Evening East Jakarta, SDN Pinang Ranti 01 
Morning East Jakarta SDN Makasar 06 Pagi East Jakarta. The following comparison of the results of the level of students' abilities to perform activities in water prior to administration of the treatments and after the treatment with an outdoor learning model for school-age students who do not dare to swim base with charts:

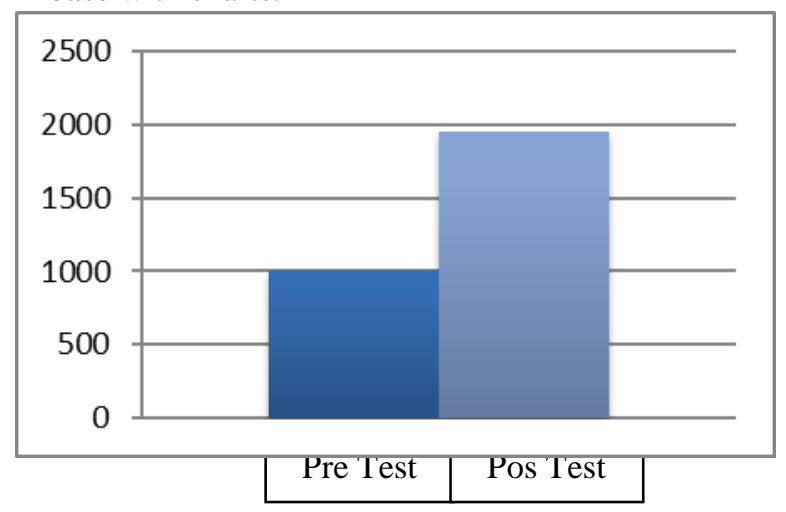

Fig. 2 The result of pretest and posttest.

According to the chart above, it can be seen that the results of small group trials and large group trials can be concluded that swimming model lessons for elementary school students who are not courageous to swim can be used in learning as well as feasible and effective to improve students' ability to perform activities in the child's water.

Based on the scoring in the table above it can be concluded that the model of swimming lesson for elementary school age students, for who not Brave Swim can and deserve to be used in an effective learning and to improve the students' activity in the water. There is a comparison of figures showing that the results of the initial test and final test progressed, from the initial tests which amounted to 1010, and was given treatment in the form of models that have been developed then held until the final test or post-test to determine the effectiveness of the models developed and the data obtained amounted to 1950, so the swimming lesson model for primary school elevate students swimmer is effective to improve students' ability to do water activities.

The swimming Lessons for the elementary school students who are developed and created by researchers are products that aim to assist teachers in delivering swimming or water activities, increasing courage and student activity abilities in water, and as reference materials. Swimming Learning Model for primary school students is made based on the level of student needs in activities learning physical education, especially swimming materials or activities in the water in elementary school. This product after reviewing some of the advantages and disadvantages that need improvement. Here are the benefits of this product:

1) Increase the courage and ability of student activity in water
2) Students become more active and enthusiastic about swimming learning

3) Students feel comfortable and secure in physical education learning

4) Lesson Learned Models for Primary School Elite Students are not Courage to Swim effectively and efficiently

5) Assist teachers in delivering swimming or water activities

6) As a reference to teaching materials

7) Contributions to science, especially physical education in school

8) Models of Swimming Learning Models for Primary Elementary School Students Dared to Swim This is done from easy to difficult.

However, the research also has drawbacks. The limitations are as follows:

1) Field trials of this research will be even better if done on a wider scope again

2) The product used is still far from perfect.

3) The facilities and infrastructure used are still limited.

Explanations and rules in the model of swimming lesson for primary school students to swim is still far from perfect.

\section{CONCLUSION}

Based on data obtained from field trial results and discussion of the results of this study concluded that the developed model can be applied in teaching physical education to improve students' ability to perform activities in the water. In addition, an outdoor learning model that has been developed and effectively to increase students' ability to perform activities in the water child..

\section{REFERENCES}

[1] Husdarta dan Yudha M. Saputra, Learn and Learning, Bandung: Alfabeta, 2013.

[2] Muarifin, The basics of physical education and Sports. Malang: UM Press, 2009.

[3] Capel, S. and Blair, R. (2007) Moving beyond physical education subject knowledge to develop knowledgeable teachers of the subject, Curriculum Journal, 18 (4), 493-507.

[4] BSNP. Guide to the preparation of the curriculum unit level of education level of primary and secondary education. Jakarta : Badan Sandar Nasional Pendidikan, 2006.

[5] Putra. History and the sense and style of swimming (www.gudangmateri.com). Retrieved on June 2015.

[6] Sugiyono. Methods of educational research, Quantitative, qualitative Approach, and $R \& D$, Bandung: Alfabeta, 2008 